\title{
An updated meta-analysis of the distribution and prevalence of Borrelia burgdorferi s.l. in ticks in Europe
}

Agustín Estrada-Peña ${ }^{1^{*}}$ (D) Sally Cutler ${ }^{2}$, Aleksandar Potkonjak ${ }^{3}$, Muriel Vassier-Tussaut ${ }^{4}$, Wim Van Bortel ${ }^{5,6}$, Hervé Zeller ${ }^{7}$, Natalia Fernández-Ruiz ${ }^{1}$ and Andrei Daniel Mihalca ${ }^{8}$

\begin{abstract}
Background: The bacteria of the group Borrelia burgdorferi s.l. are the etiological agents of Lyme borreliosis in humans, transmitted by bites of ticks. Improvement of control measures requires a solid framework of the environmental traits driving its prevalence in ticks.

Methods: We updated a previous meta-analysis of the reported prevalence of Borrelia burgdorferi s.l. in questing nymphs of Ixodes ricinus with a literature search from January 2010-June 2017. This resulted in 195 new papers providing the prevalence of $\mathrm{Bb}$ for 926 geo-referenced records. Previously obtained data (878 records, years 2000-2010) were appended for modelling. The complete dataset contains data from 82,004 questing nymphs, resulting in 558 records of B. afzelii, 404 of B. burgdorferi s.s. (only 80 after the year 2010), 552 of B. garinii, 78 of B. lusitaniae, 61 of B. spielmanii, and 373 of $B$. valaisiana. We associated the records with explicit coordinates to environmental conditions and to a categorical definition of European landscapes (LANMAP2) looking for a precise definition of the environmental niche of the most reported species of the pathogen, using models based on different classification methods.

Results: The most commonly reported species are B. afzelii, B. garinii and B. valaisiana largely overlapping across Europe. Prevalence in ticks is associated with portions of the environmental niche. Highest prevalence occurs in areas of $280^{\circ}-290^{\circ}$ (Kelvin) of mean annual temperature experiencing a small amplitude, steady spring slope, together with high mean values and a moderate spring rise of vegetation vigor. Low prevalence occurs in sites with low and a noteworthy annual amplitude of temperature and the Normalized Difference Vegetation Index (colder areas with abrupt annual changes of vegetation). Models based on support vector machines provided a correct classification rate of the habitat and prevalence of $89.5 \%$. These results confirm the association of prevalence of the three most commonly reported species of B. burgdorferi s.l. in Europe to parts of the environmental niche and provide a statistically tractable framework for analyzing trends under scenarios of climate change.
\end{abstract}

Keywords: Borrelia burgdorferi s.l., Meta-analysis, Distribution, Europe, Modelling of prevalence

\section{Background}

The genus Borrelia is a large assemblage of bacterial species, which gained a great deal of attention in the last decades due to their importance for human health [1-3]. Lyme borreliosis, caused in humans by several species in the Borrelia burgdorferi s.l. complex (hereinafter Bb),

\footnotetext{
*Correspondence: aestrada@unizar.es

${ }^{1}$ Department of Animal Health, Faculty of Veterinary Medicine, Miguel

Servet 177, 50013 Zaragoza, Spain

Full list of author information is available at the end of the article
}

is considered the archetype of an emerging infectious disease [4]. Information on the geographic distribution of the different species of $\mathrm{Bb}$ is of great epidemiological importance because the different species are associated with different clinical outcomes. Recent studies of the distribution of $\mathrm{Bb}$ in Europe focused on geographic analyses, based on administrative divisions, which do not follow natural ecological regions and cannot address the importance of environmental traits in the reported prevalence of $\mathrm{Bb}$ in ticks [5]. These bacteria circulate in 
natural complex cycles involving ticks and vertebrates. The large complexity of the natural networks allowing circulation of $\mathrm{Bb}$ has already been pointed out [6]. Some "bridge ticks" [7] act as transmitters of the pathogen to humans, while other tick species might support circulation of $\mathrm{Bb}$ in silent foci. These ticks do not commonly bite humans, therefore the presence of the pathogen is hard to realize in the absence of human clinical cases.

The spatial distribution of the medically relevant tick vectors in Europe (I. ricinus and I. persulcatus) is far from uniform. It has been suggested that the adaptations of tick species and vertebrate hosts to the local climate contribute to the spatial distribution patterns of $\mathrm{Bb}$ [8-10]. It is well known that $\mathrm{Bb}$ species circulate in different vertebrate reservoirs [9]. Further, a recent study suggested a clear association between genotypes of $\mathrm{Bb}$ species and tick species $[6,11]$. It is thus necessary to consider the associations between ticks, reservoirs and environment to understand the occurrence of $\mathrm{Bb}$. Hence, changes in the distribution of both the vector and the reservoirs is expected to impact the spatial distribution of $\mathrm{Bb}$ in Europe [12].

The prevalence and distribution of $\mathrm{Bb}$ in I. ricinus in Europe have been reviewed $[13,14]$ and meta-analyses of the prevalence of $\mathrm{Bb}$ species in I. ricinus ticks in Europe have already been performed $[5,15,16]$. The distribution of I. ricinus and I. persulcatus continues to expand northwards in latitude and upwards in altitude in Europe [12, $17-24]$. Climate trends and the density of key hosts for the adults of the tick, have been pointed as the main factors behind the spread of I. ricinus [12, 23, 25].

Considering all these aspects, it is therefore necessary to (1) update previous meta-analyses of the distribution of Bb ticks in Western Palearctic, (2) improve our knowledge of the determinants of the observed distribution of $\mathrm{Bb}$ in ticks, and (3) build a synthetic explanation of such interacting factors driving the reported prevalence in questing ticks. Here, we updated our previous metaanalysis [16] of the reported prevalence and distribution of $\mathrm{Bb}$ in host-seeking I. ricinus ticks in Europe based on a systematic literature review. We also included in our analysis $B$. miyamotoi, a relapsing fever species, because of the growing concerns about its importance [26]. In this study we (1) describe the occurrence and prevalence of the species of $\mathrm{Bb}$ in I. ricinus in Europe and (2) the environmental traits that drive the reported prevalence of the most common Bb species in questing I. ricinus.

\section{Materials and methods}

\section{Data collection, assemblage of the primary dataset and data cleaning}

This study is based on the collection of published reports about the prevalence of $\mathrm{Bb}$ in questing nymph ticks (see
Fig. 1 for data collection strategy). We also included data on B. miyamotoi. We did not include the prevalence of $\mathrm{Bb}$ in wild, domestic animals or humans, nor data reported in feeding ticks. The former tends to introduce bias in the reports, because some vertebrates may be more efficiently trapped compared to scarce or protected species, which are therefore under-represented in reports even if they prominently harbour $\mathrm{Bb}$. The latter always distort the rates of carried micro-organisms in ticks, because DNA amplification methods cannot differentiate between DNA of the pathogen that was already in the tick or was a consequence of the blood meal [27].

The bibliographical search was performed in PubMed, Google Scholar, and The Web of Knowledge, for the period January 2010-June 2017 using the words ("Ixodes" OR "Ixodidae" OR "Tick") AND ("Borrelia") AND ("Europe" OR [list of countries of European Union, EEA, and Balkan countries]). This query was deliberately relaxed since we observed in preliminary tests that other combinations of keywords resulted in a loss of published papers reporting the prevalence of $\mathrm{Bb}$ in ticks. The target territory included the 28 European Union Member States together with Iceland, Liechtenstein, Norway, Switzerland and the Balkan countries. Title and abstract were screened to remove the papers not dealing with the prevalence of $\mathrm{Bb}$ in ticks. Papers describing mainly clinical manifestation(s) in humans or prevalence of $\mathrm{Bb}$ in vertebrates were included in the dataset only if they reported also data of prevalence in questing ticks. Papers reporting the results as "B. burgdorferi s.l." were used for updating the main distribution data, even if no names of species were provided, but data were not used for modelling. We included only reports with a pair of coordinates or for which the name of the collection locality could be unambiguously referred to a pair of coordinates. The final dataset of the period 2010-2017 was updated with geo-referenced data of prevalence of $\mathrm{Bb}$ in questing ticks from a previous, similar study [16]. Only data from questing nymphs were used, since adult ticks are more infrequently collected, and they had two different blood meals, thus complicating further analyses. Moreover, nymphs are the most common stage feeding on humans. Some papers reported the data referred to pools, and subsequently the prevalence in each pool was used.

A critical issue in this kind of meta-analysis is the number of ticks collected, analyzed and reported. To avoid bias in the modelling of the data, we included only studies that comprised a sufficient number of nymphal ticks in the study. We established the threshold of the minimum sample size as the 10th percentile of the dataset. This corresponds to a minimum of 29 questing nymphs for each sampling point. This choice was done after a visual inspection of the number of ticks 


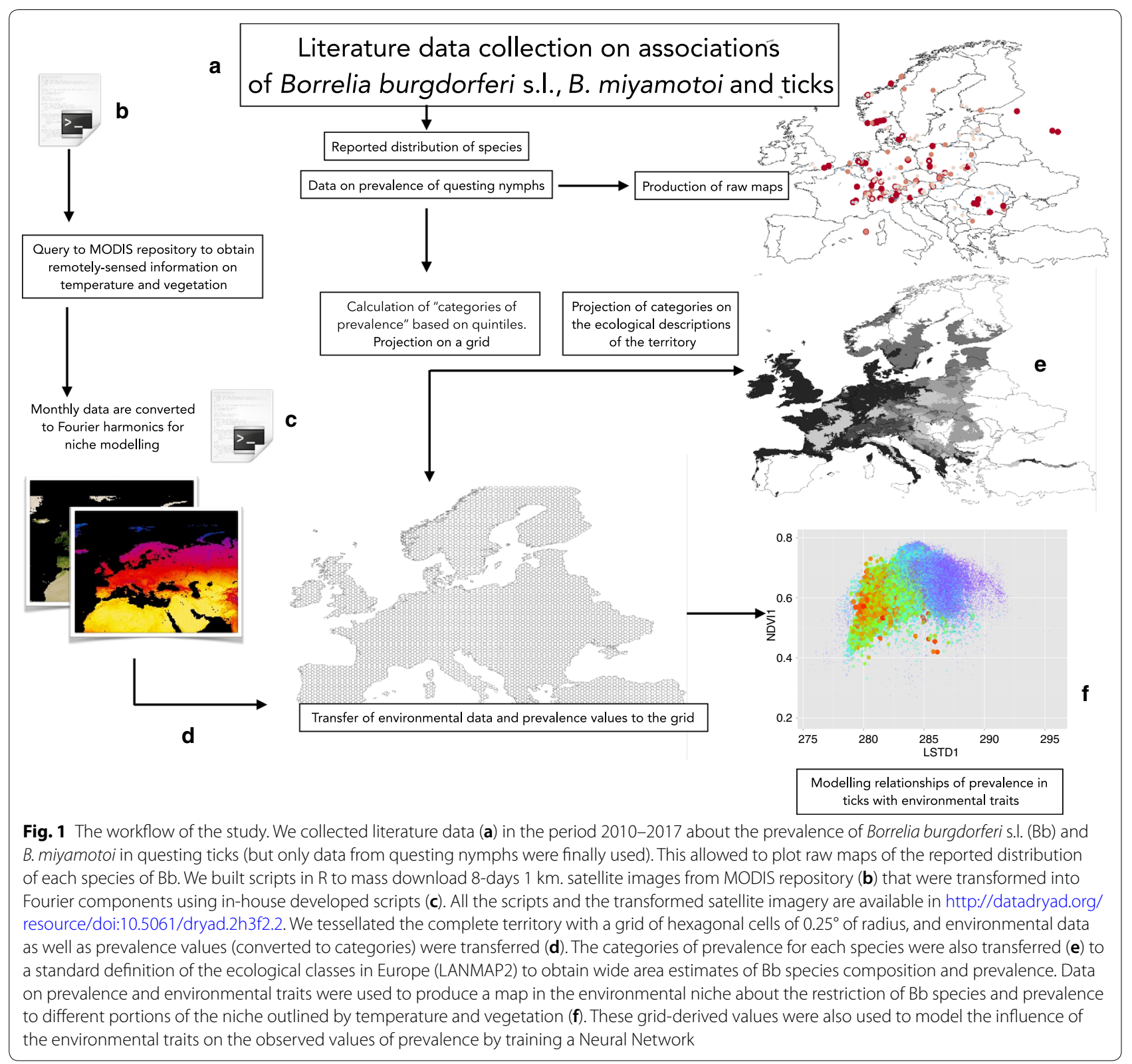

tested against the prevalence: lower numbers of ticks were always associated with higher prevalence, therefore biasing the outcome of the analysis. We did not test the potential influence of a lower number of ticks on the modelling: we thus adhered to the inclusion of a minimum number of ticks by report based on the pure frequency distribution of the data. The phenology of the tick and the date of collection were not considered, and we refer to the "site" (i.e. the pair of coordinates) independently of the number of surveys carried out in a period of time in the same site, including only those which were above the minimum threshold, and averaging the values of prevalence.

\section{Sources of climate and ecological data}

We aimed to establish a link between the environmental niche and prevalence of $\mathrm{Bb}$ in questing nymphal $I$. ricinus according to a scheme with ecological meaning. We exploited a series of remotely sensed variables describing the ground temperature (in Kelvin) and the Normalized Difference Vegetation Index (NDVI). The NDVI is a measure of the photosynthetic activity of the vegetation, and is influenced by the types of canopy and soil and the leaf shape. However, it is known that the length of the vegetative period (as recorded by NDVI) is an important feature for capturing the distribution of ticks and the presence/absence of $\mathrm{Bb}$ [21]. For 
modelling purposes, we used the Fourier-transformed remotely sensed imagery because it represents the best balance between a low number of explanatory variables with an adequate description of the climate traits [6, 28]. The Fourier transform (or harmonic regression) uses a series of weather data to extract its main factors, as the mean of the series of values, the slope at the spring or the (negative) slope of autumn. We demonstrated that only three variables account for the mean values of temperature, the spring rise, the duration of the summer, the decrease and the negative slope in autumn, or the duration and mean values of temperature of autumn and winter, which adequately represent the environmental niche of ticks [28]. We already made publicly available the raster explanatory variables and the scripts to obtain them from time series data, which can be accessed at http://datadryad.org/resou rce/doi:10.5061/dryad.2h3f2.2. We used three variables for temperature and three for NDVI.

We used the GlobCover system to obtain the dominant vegetation and the fragmentation of the territory, to be used together with the climate variables as ecological descriptors of the distribution and prevalence of $\mathrm{Bb}$. GlobCover is a global classification based on ENVISAT's MERIS satellite, at a resolution of 300 meters (available at http://geodata.grid.unep.ch/mod_download/download. php, accessed August, 2017). Other European standards, like CORINE, lack the adequate number of categories necessary to describe the habitat of ticks.

\section{Analysis of the data and statistical methods Plotting the prevalence of $\mathrm{Bb}$ in questing nymphs}

We did crude plots of the reported prevalence of every species of $\mathrm{Bb}$. We did not attempt to extrapolate any conclusion about trends of prevalence over time, using data for the periods 2000-2010 and 2010-2017. The patchy nature of the reports, randomly covering small portions of the wide target territory (i.e. surveying rather small territories for periods of different time length) precluded an assessment of trends over time for prevalence of $\mathrm{Bb}$ in questing nymphs.

\section{General procedures}

We first tessellated the target territory with a grid of hexagons, $0.25^{\circ}$ (decimal degrees) radius for each cell. Both dominant vegetation and the number of different classes of vegetation were obtained for each cell of the grid covering the target territory. We included in each cell of the grid the climate-derived explanatory variables. Data on dominant vegetation (the most represented category of vegetation) and habitat fragmentation (the number of different vegetation categories) in each cell of the grid were added to the satellite-derived weather variables to explain the prevalence of $\mathrm{Bb}$ in questing ticks. Other than the tessellation of the territory for modelling purposes, we aimed to link the prevalence of $\mathrm{Bb}$ across rough descriptions of the climate of Europe. We adhered to previous approaches $[29,30]$ using the European Landscape Map, LANMAP2, a pan-European landscape database at a scale of 1:2,000,000 [31]. LANMAP2 is a hierarchical classification with four levels and has 350 landscape types at its lowest level. At this level there are more than 14,000 mapping units with an average size of $774 \mathrm{~km}^{2}$. The highest level of the classification is determined by climate and has only eight classes; the smallest mapping unit is $11 \mathrm{~km}^{2}$. These raw data are available as Additional file 1 , and include the original records with coordinates, as well as the environmental variables associated with each record, including continuous (i.e. MODIS-derived) and categorical data (i.e. LANMPA2 and GlobCover) as used for further statistical processing.

\section{Capturing the relationships between the environmental niche and the prevalence of $\mathrm{Bb}$ in questing ticks}

We used the grid data to model the relationships between combinations of climate and landscape variables with the prevalence of $\mathrm{Bb}$ in questing nymphs of $I$. ricinus. The cells of the grid covering the territory for which prevalence data exist were loaded with the reported value(s) of prevalence, as the variable to be explained by the climate and landscape (dominant vegetation and habitat fragmentation) traits. The rather disparate prevalence of $\mathrm{Bb}$ in questing nymphs in geographically close surveys produced a background noise, since two or more reports with very different prevalence values could overlap in the same cell. In this case, if two or more reports were in the same cell of the grid, the weighted average of the reported prevalence, based on the number of processed ticks, was used.

For the same reasons, we opted to reclassify the values of prevalence of $\mathrm{Bb}$ in the cells of the grid into categories. We used the quintiles of the frequency distribution of the reported prevalence of each Bb species in questing nymphs to establish the following categories: "absent" (<1\%), "very low" (1-4\%), "low" (4-9\%), "medium" (9-21\%), "high" (21-46\%) and "very high" (>46\%). Some species, like B. spielmanii, B. finlandensis, or $B$. miyamotoi (not a Bb species) were scarcely reported (less than 10 reports) or even not reported in questing nymphs of I. ricinus and were therefore not subjected to further statistical analyses. Table 1 includes the number of records available for the categories of prevalence of Borrelia afzelii, B. garinii and $B$. valaisiana, which were the most commonly reported species of $\mathrm{Bb}$. 
We trained models built with Neural Networks, Naive Bayes, AdaBoost (short for Adaptive Boosting) and support vector machines in the "Orange" programming environment version 3 (https://orange.biolab.si) aimed for developing the best model classifying each cell according to the class of prevalence of $\mathrm{Bb}$. The selection of algorithms was not intended to be exhaustive, and we used the four methods producing the best results in preliminary tests. For every method, models were trained with a random selection of $50 \%$ of grid cells of each category. However, algorithms have different sensitivity to data imbalance. The only condition for data entering was that the total number of cells in the category "absent" was not higher than the sum of the grid cells of the other categories. The "absent" category can produce unexpected results because the "absence of $\mathrm{Bb}$ " could be derived from its real absence or because the randomly chosen grid entering into the training set has not been surveyed. To avoid this potential bias, we included the condition of "vector being present" as an additional condition; therefore, only the grid cells with the category "Bb absent" and vector "present" were introduced in the training set for modelling.

The best neural network was obtained with 100 neurons in one hidden layer, activated by the ReLu (rectified linear unit) function and the L-BFGS-B solver, with alpha $=0.0001$ and 200 maximum iterations. For Naive Bayes we assumed equiprobable classes (i.e., priors $=1$ / (number of classes)). For AdaBoost, we used the option "tree" as base estimator, with 50 estimators and a learning rate of 1 , using the SAMME.R as classification algorithm and the linear regression loss function. For SVM, we used a RBF kernel, with a maximum of 100 iterations and a tolerance 0.001 . These values were selected after preliminary tests aimed to choose the best combination of base estimators. The data on the effects of parameter selection

\begin{tabular}{|c|c|c|c|}
\hline Category & Borrelia afzelii & Borrelia garinii & $\begin{array}{l}\text { Borrelia } \\
\text { valaisiana }\end{array}$ \\
\hline Absent & 42 & 55 & 65 \\
\hline Very low & 106 & 143 & 116 \\
\hline Low & 131 & 123 & 91 \\
\hline Medium & 132 & 99 & 70 \\
\hline High & 66 & 74 & 21 \\
\hline Very high & 81 & 58 & 10 \\
\hline Total & 558 & 552 & 373 \\
\hline
\end{tabular}

Categories are "absent" (<1\%), "very low" (1-4\%), "low" (4-9\%), "medium" (9-21\%), "high" (21-46\%) and "very high" (>46\%) in modelling are not explicitly included but are available using Additional files 2 and 3. Because of limited data availability for other species of $\mathrm{Bb}$, we performed the modelling only with the best represented ones, namely $B$. afzelii, B. garinii and B. valaisiana. The script for modelling based on the "Orange" programming environment is available as Additional file 2, together with the dataset entered to produce the models, available as Additional file 3. The script needs the download of the software (freely available) to run.

\section{Results}

\section{Description of the reported data}

We compiled a total of 195 papers providing the prevalence of $\mathrm{Bb}$ in questing I. ricinus in the period January 2010-June 2017. The reports of this period included a total of 36,894 ticks. The complete dataset of prevalence in questing nymphs, with adequate identification of the $\mathrm{Bb}$ species and with a sample size of nymphs above the $10 \%$ of the frequency distribution consisted in 1177 records, of which 926 had adequate information about coordinates. A further set of 878 records (years 20002010, with geo-references, see Estrada-Peña et al. [16]) has been added to the 2010-2017 dataset. This produced a total of 558 geo-referenced records of B. afzelii, 404 of B. burgdorferi s.s. (only 80 after the year 2010), 552 of $B$. garinii, 78 of B. lusitaniae, 61 of B. spielmanii, 373 of $B$. valaisiana, and 29 of B. miyamotoi. Borrelia finlandensis and B. turdi have been reported (2010-2017) only in feeding ticks and/or in host tissues, and these records are therefore not included.

Figures 2, 3, 4 and 5 show the geographical pattern of prevalence of the five species of $\mathrm{Bb}$ in questing nymphs for which examined specimens were above the threshold limit, over the period 2000-2017. Figure 6 displays the overview of the prevalence of $\mathrm{Bb}$ s.l. in questing nymphs in the target territory. The figure has been produced with reports resulting from 82,004 questing nymphs (years 2000-2017), after the removal of the records reporting a sample size below the $10 \%$ threshold established for analysis. The visual inspection of these figures does not provide clues about a spatial pattern for the species of $\mathrm{Bb}$ or their prevalence in questing nymphal ticks. The main point from these maps is that $\mathrm{Bb}$ exists at very variable rates anywhere the vector exists, with maximum prevalence at large regions of central Europe. The pathogen tends to be less prevalent at the fringe of its distribution, probably because the colder conditions restricting vector resilience (i.e. Baltic countries) or because the lack of adequate reservoirs (i.e. United Kingdom). In any case, the reported prevalence is very patchy across the target territory. It is necessary to observe that the patchy spatial pattern of presence-absence is the consequence of a 


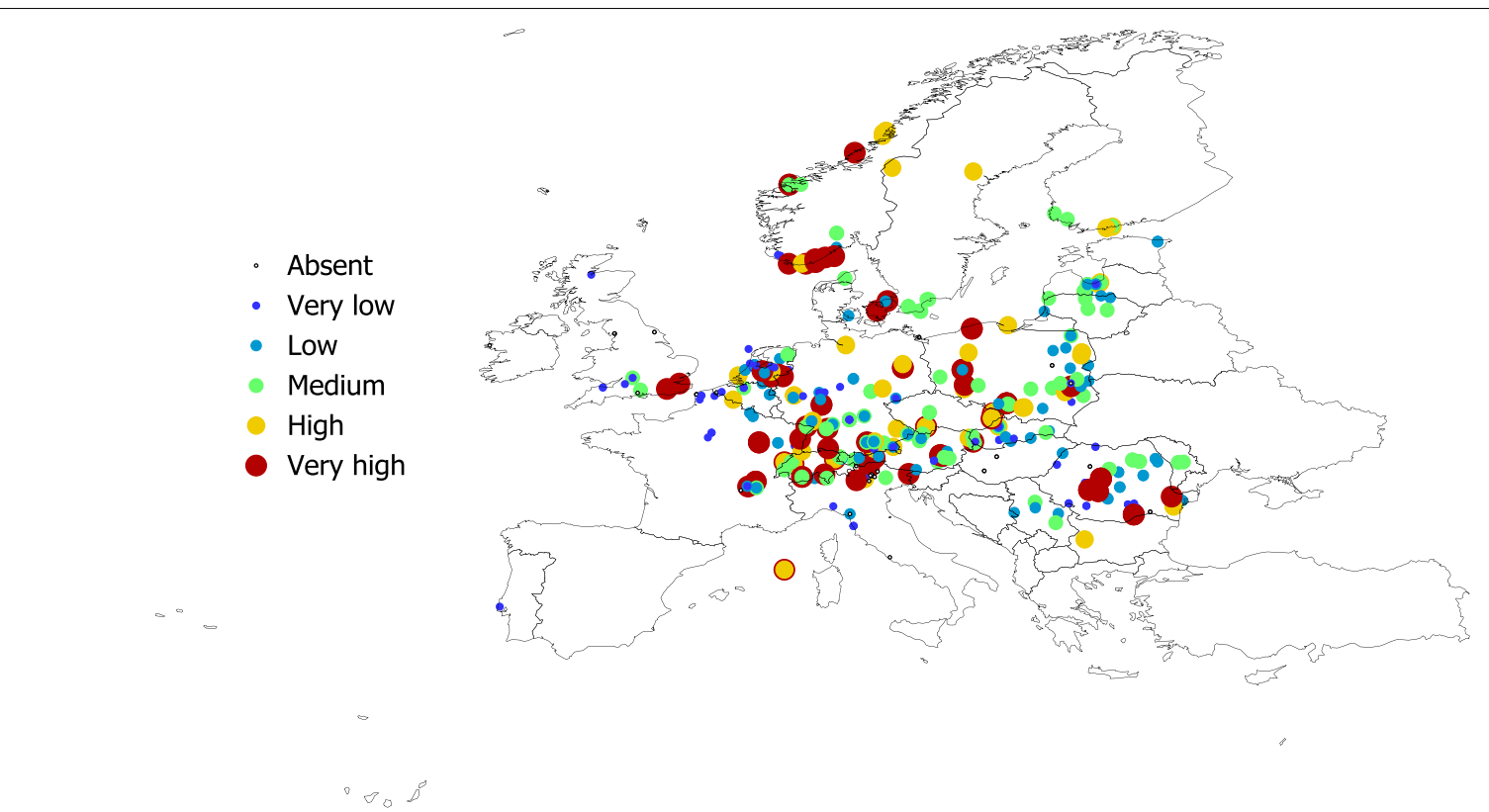

Fig. 2 The reported distribution and prevalence of B. afzelii in questing nymphs of I. ricinus (data for years 2010-2017). The size and the levels of grey of the plots in the legend define the prevalence at the coordinates of the points

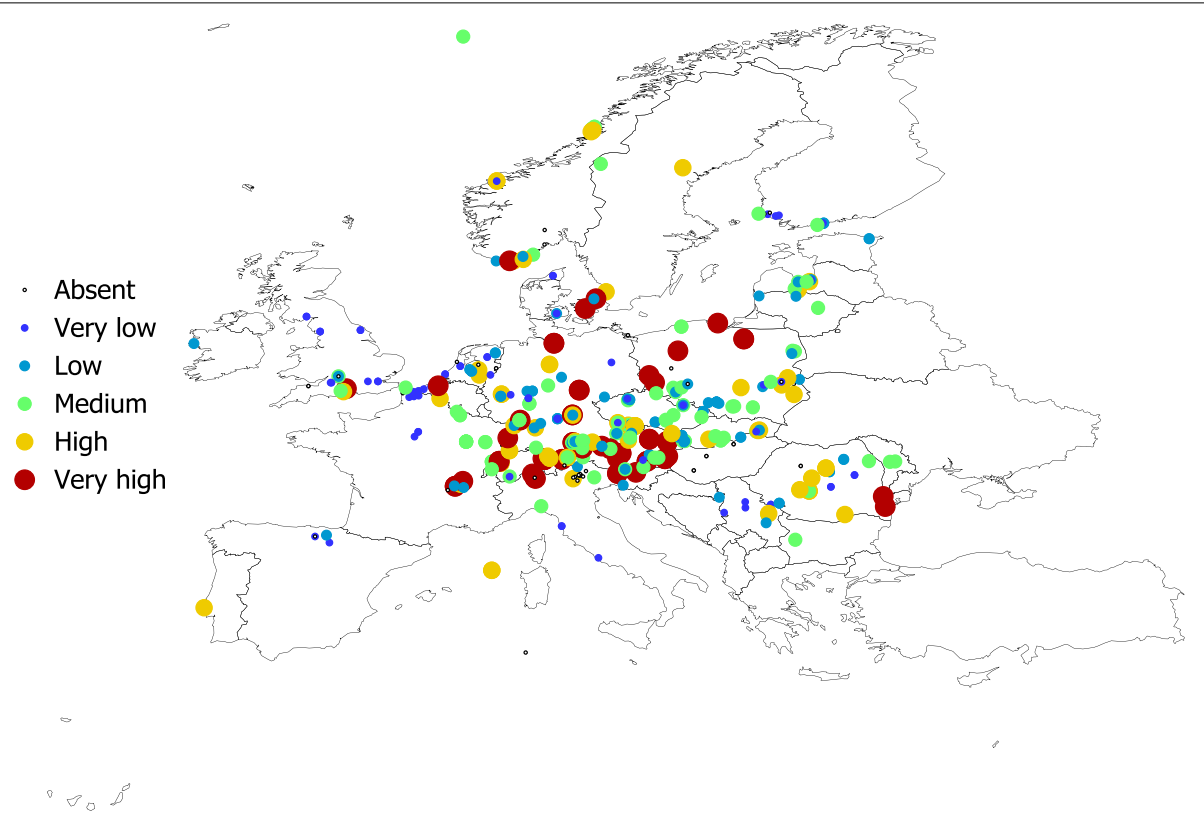

Fig. 3 The reported distribution and prevalence of B. garinii in questing nymphs of I. ricinus (data for years 2010-2017). The size and the levels of grey of the plots in the legend define the prevalence at the coordinates of the points

meta-analysis, in which the surveys have not been previously planned. However, the sudden changes of prevalence for spatially near reports should be considered as the actual patchy distribution of these rates.
The cross-tabulation histogram of the prevalence of $B$. afzelii, $B$. garini $i$, and $B$. valaisiana against the general types of climate (as provided by LANMAP2 classification) is included in Fig. 7. This cross-tabulation produced observable differences between the prevalence of 


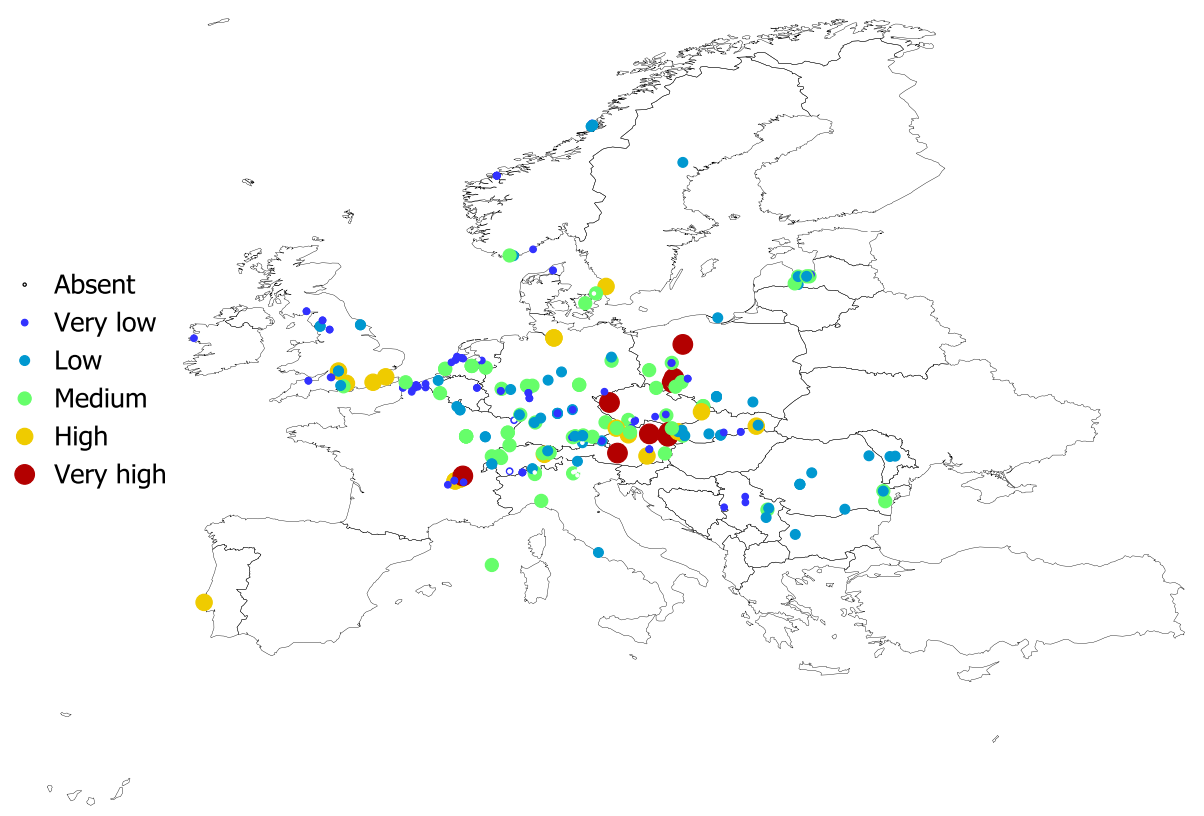

Fig. 4 The reported distribution and prevalence of B. valaisiana in questing nymphs of I. ricinus (data for years 2010-2017). The size and the levels of grey of the plots in the legend define the prevalence at the coordinates of the points

a

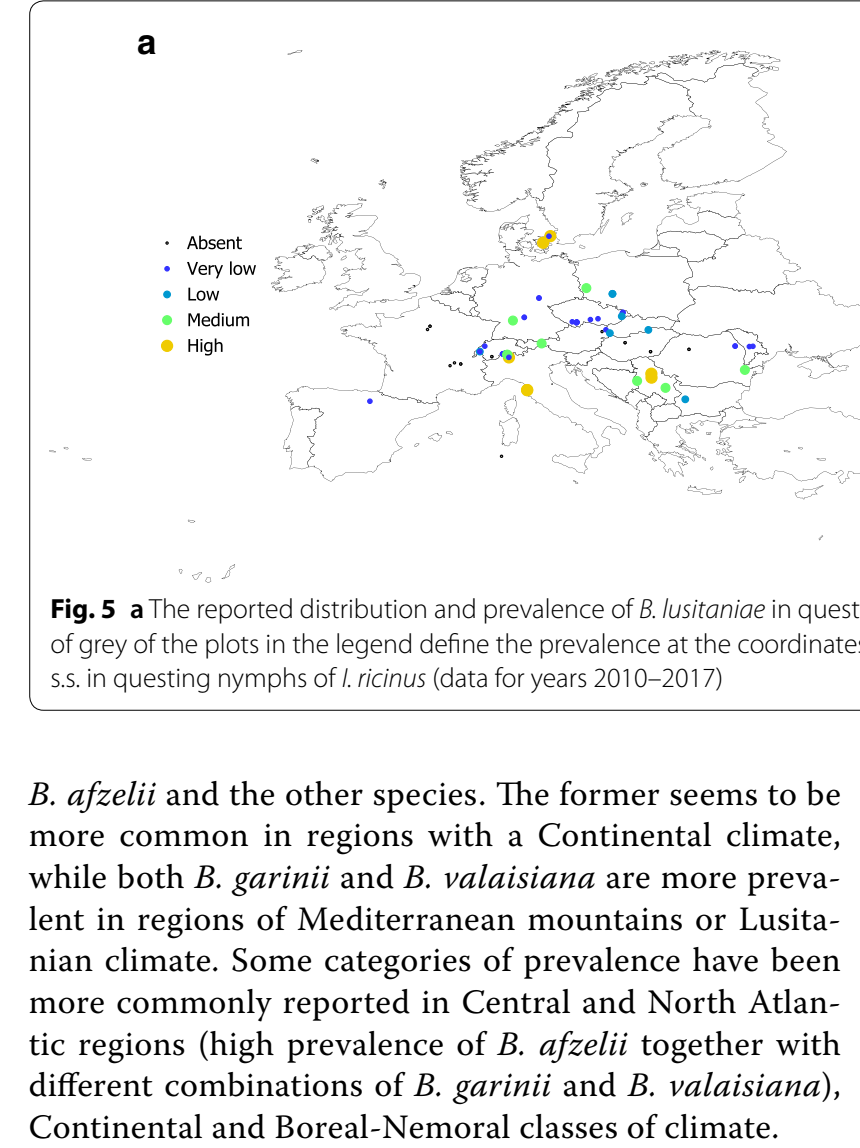

B. afzelii and the other species. The former seems to be more common in regions with a Continental climate, while both $B$. garinii and B. valaisiana are more prevaent in regions of Mediterranean mountains or Lusitaveen tic regions (high prevalence of $B$. afzelii together with different combinations of $B$. garinii and B. valaisiana) Continental and Boreal-Nemoral classes of climate.

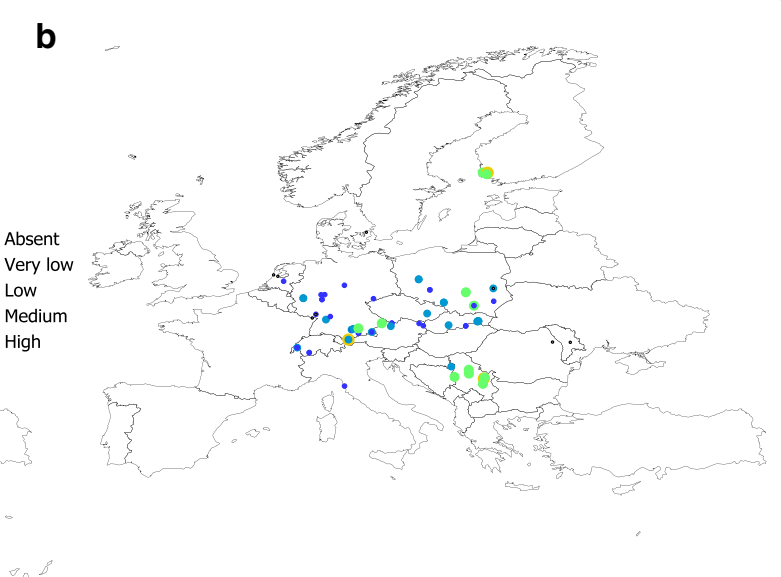

nymphs of I. ricinus (data for years 2010-2017). The size and the levels the points. $\mathbf{b}$ The reported distribution and prevalence of $B$. burgdorferi Modelling uncovers a pattern of spatial distribution for $\mathrm{Bb}$ in Europe

The classification of the categories of prevalence produced good modelling results, using only temperature and NDVI -derived variables. The SVM over-performed the rest of the modelling approaches (Table 1). The SVM produced a correct classification rate of more than $98 \%$ and 99\% (the former for B. afzelii and B. garinii, the later for B. valaisiana), with an AUC (area under the curve, commonly used to explain together true positives and 


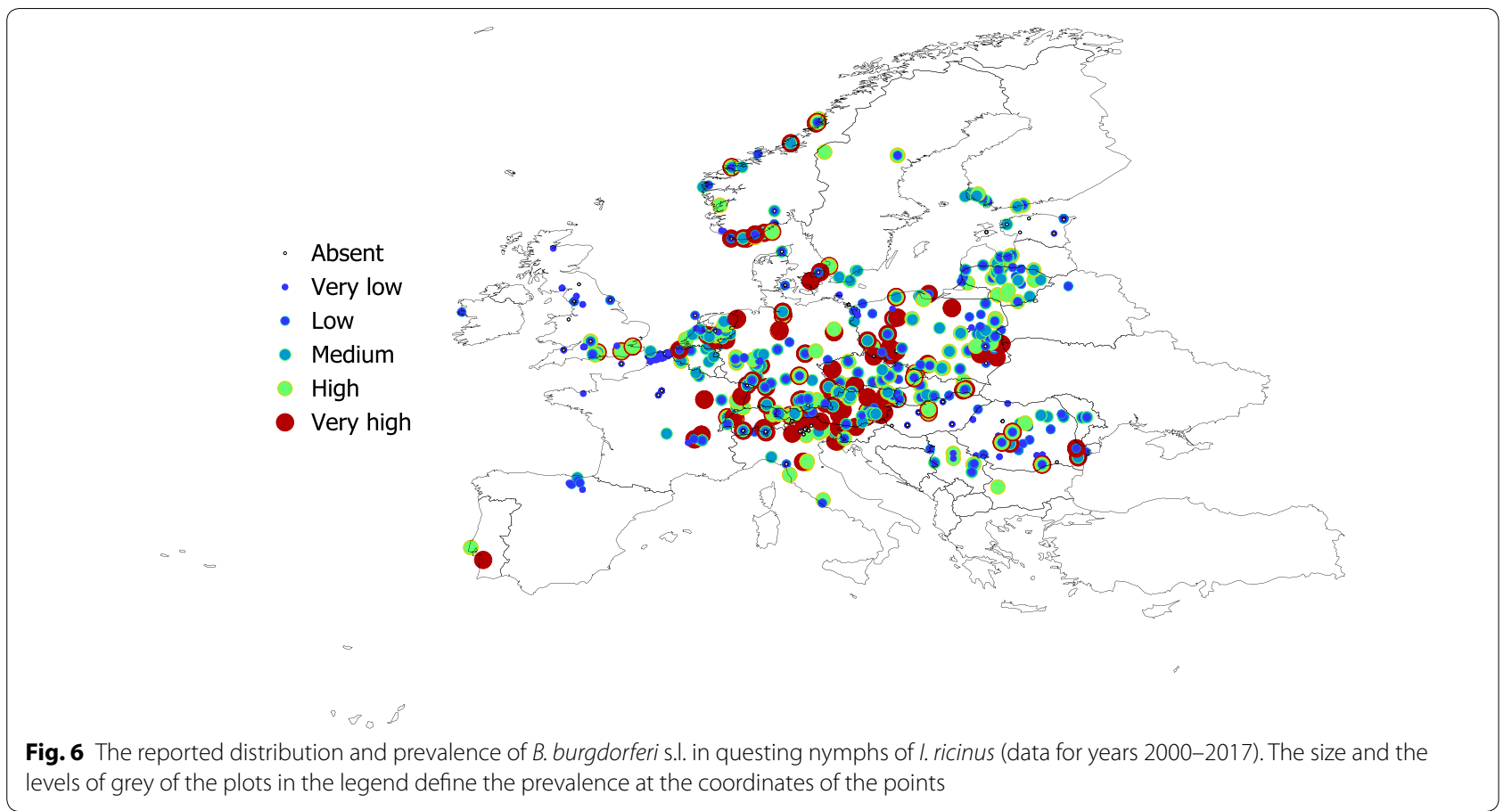

false positive rates) higher than 0.81 for every species (in the range $0-1$ ). We thus used SVM, the six temperatures and NDVI variables, to classify the target territory with the predicted prevalence of these three species, and the results were plotted over the LANMAP2 bioclimate regions of the target territory (Fig. 8). It resulted that the prevalence categories of the three most reported species of $\mathrm{Bb}$ shows a geographical pattern, unforeseeable from the representation of the crude prevalence as reported. While the three species show a wide distribution in Europe, the expected prevalence of each species is very different. Borrelia afzelii tends to be common in most of Central Europe and Atlantic regions, with low prevalence in the periphery of its distribution. The prevalence of B. garinii, however, shows a patchier distribution, with large areas of the Atlantic and central European regions included in the "very high" category. Borrelia valaisiana is also expected to be frequent in questing nymphal $I$. ricinus mainly in coastal areas and central Europe, with medium values of prevalence in central Europe. All these three species tend to be rare in the margins of their range (Table 2).

\section{The prevalence of $\mathrm{Bb}$ is associated with environmental features}

We aimed to visually capture the relationships of the predicted prevalence categories with the environmental traits for the three modelled $\mathrm{Bb}$ species. The focus was to check if there were "portions" of the environmental niche in which prevalence of categories were different, or, in other words, if the predicted prevalence is associated to a delimited portion of the environmental variables. This would result in a framework that could be subjected to analysis of change or resilience according to different climate scenarios. Figures 9, 10 and 11 group the plots of prevalence classes against two variables of temperature and one of NDVI (annual mean and slope in spring for temperature; annual mean temperature and annual mean NDVI). There is an overlap in some portions of the environmental niche defined by these variables: there is no evidence of an "environmental barrier" clearly separating prevalence classes. Most importantly, however, these three species of $\mathrm{Bb}$ co-occur at some portions of the environmental niche at different prevalence, delimited by the annual mean values and the slope in spring of both temperature and NDVI. The conclusion is that there are features in the environmental niche that promote different rates of co-occurrence of these species, revealed as different prevalence categories in close portions of the environment. Both B. afzelii and B. garinii tend to occur at different parts of the niche defined by the temperature, but not well delimited by NDVI. Borrelia valaisiana shows a patchier distribution along the main axes of the environmental niche (something already observed in the geographic space). With the obvious hesitation regarding the modelling procedures and the unplanned surveys resulting in a meta-analysis, these results indicate that environmental variables are associated to the prevalence 


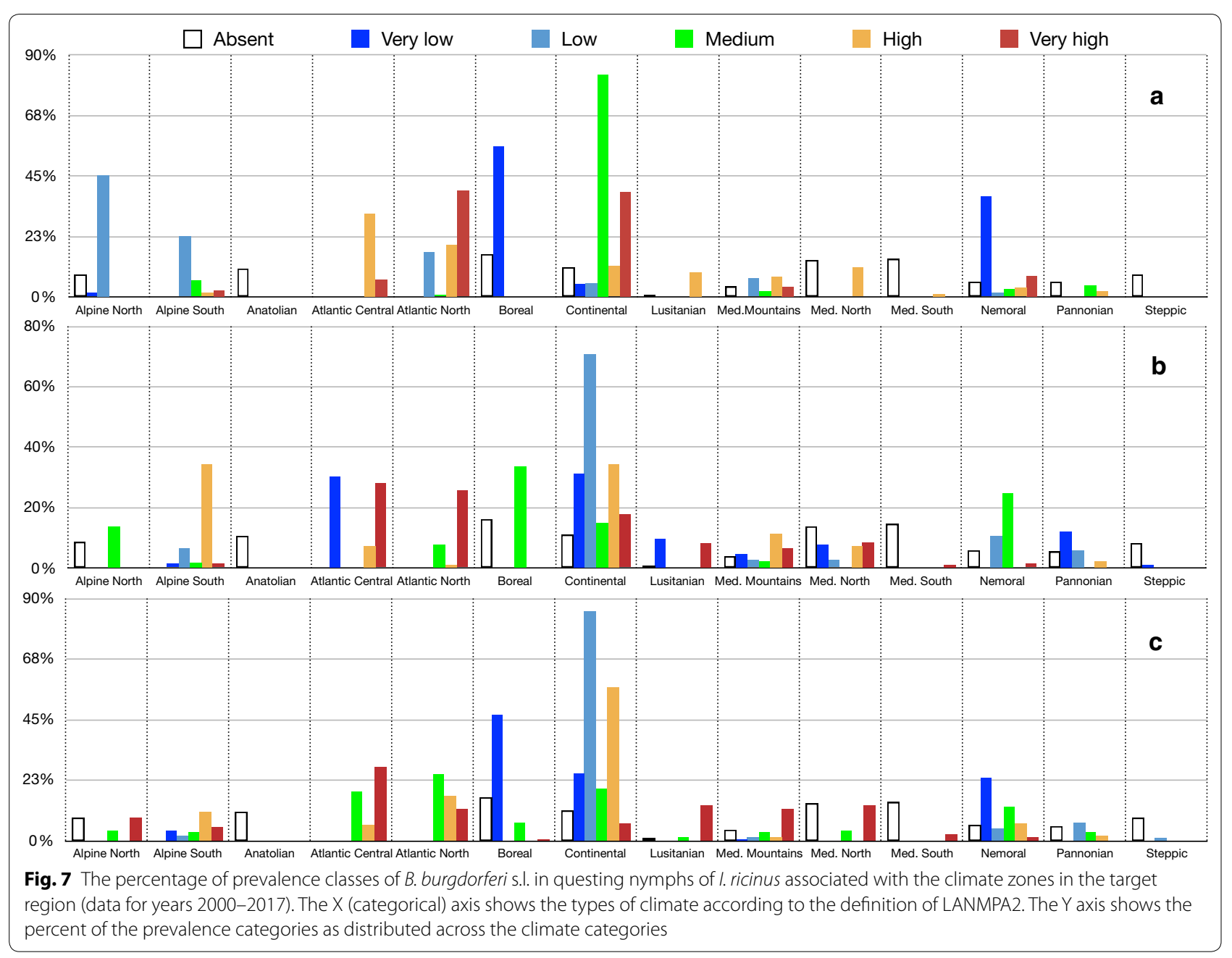

categories of the three most reported species of $\mathrm{Bb}$ in Eur ope.

\section{Discussion}

This study updates a previous meta-analysis [16] on the prevalence of $\mathrm{Bb}$ in questing nymphs of $I$. ricinus in Europe using reports published between 2010 and mid-2017, improving our knowledge of the range of $\mathrm{Bb}$ in Europe. The data for the period 2010-2017 (>36,000 questing nymphs) were updated with data from the period 2000-2009 (> 43,000 questing nymphs). The current study thus represents the largest analysis of the distribution of the pathogen in questing nymphs of $I$. ricinus in Europe. We used only data from questing nymphs because of the unreliability of reports in ticks collected and processed while feeding; questing nymphs are also the more abundantly collected stage of $I$. ricinus. This study has obvious limitations that emanate from the structure of the data sources. We could not analyze temporal trends from the reports because of the lack of a coherent background, which should be ideally structured around the same methods. While we acknowledge that a temporal analysis of prevalence trends for $\mathrm{Bb}$ in questing ticks would be necessary, meta-analysis is not an adequate framework if surveys have used heterogeneous methodological approaches. A meta-analysis is built from unplanned surveys, with data obtained using a large variety of methods with different reliability. Also, the spatial resolution used in this study, aimed to provide a coherent background at a relatively rough resolution, cannot capture the local nature of the foci of $\mathrm{Bb}$. Moreover, the systematics of this group of bacteria have undergone recent important changes [9]. Consequently, caution is needed when examining old reports of some species. We prefer to be conservative about these data. For example, most records of B. burgdorferi s.s. (2000-2010) were published before the description of new species within the group [32-34] with a sudden drop of records correlating with use of probes that are able to separate species of $\mathrm{Bb}$. It is a well contrasted fact that B. burgdorferi s.s. tends to 


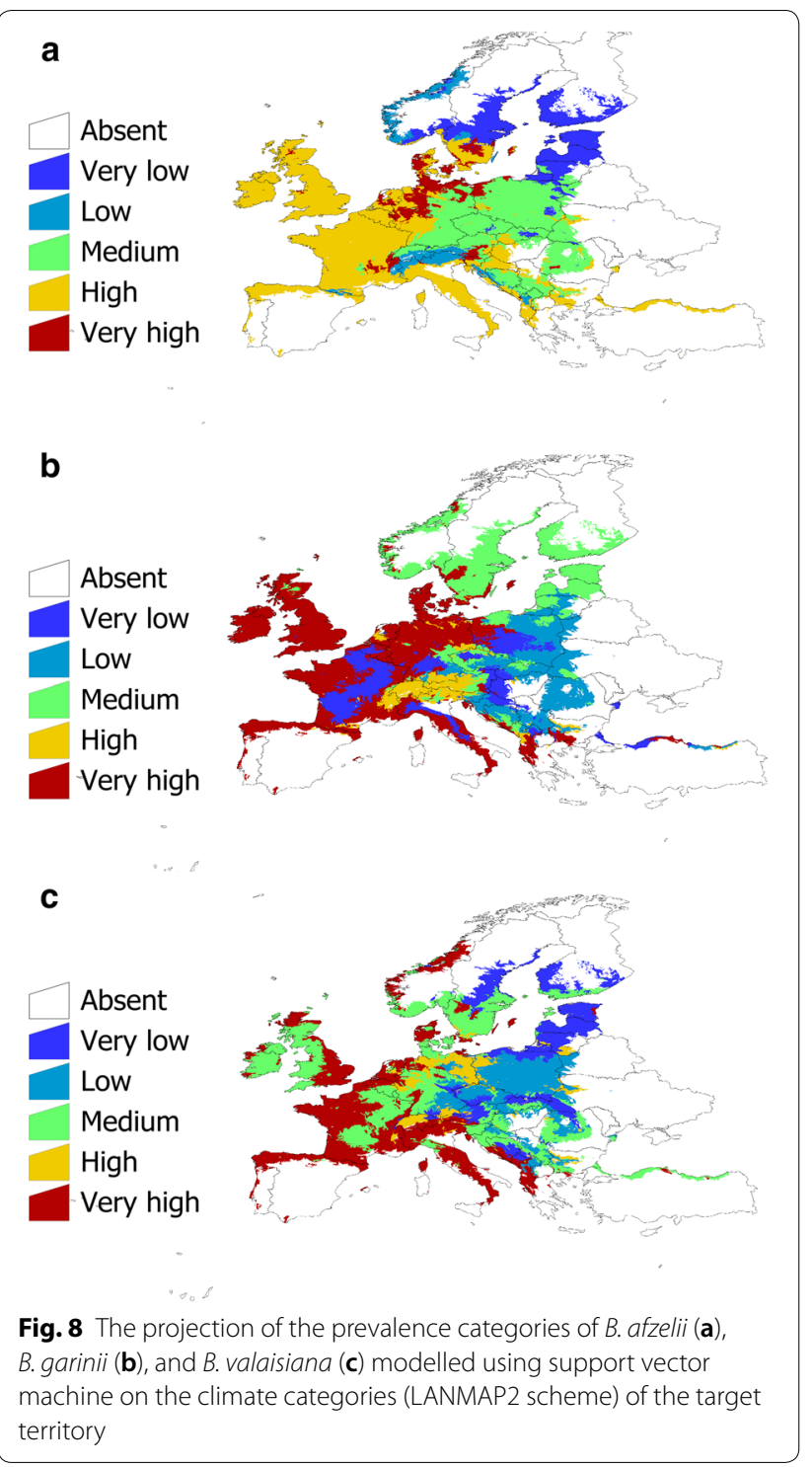

be rare in the Western Palearctic (Margos, pers. comm.). This is why B. burgdorferi s.s. was not included in modelling, because reliable records are scarce, and old records (approximately pre-2010) might actually correspond to other species.

Our results provided additional support to previous reports about the spatial prevalence of $\mathrm{Bb}$ in questing nymphs of I. ricinus: the surfaced pattern shows the highest prevalence and the largest combination of $\mathrm{Bb}$ species in parts of central Europe, associated with Continental or North Atlantic-type of climates. These findings contradict early reports $[7,15,35]$ a fact probably derived from the bias produced by tabulating reports according to administrative divisions. In general, the updated results outline the already reported range of $\mathrm{Bb}[16]$. However, the focus of the current study on the most frequently reported species and the use of categorical values of prevalence produced a sharper picture of both the spatial pattern of $\mathrm{Bb}$ and the relationships of prevalence with the environmental traits.

The raw quantitative values of prevalence produced a noise which was removed by partitioning the data using the quantiles of its distribution, producing a statistically coherent aggregation of data. Several other strategies have been employed in this study, to improve data mining, summarizing resulting information, and improving modelling, like (a) the use of satellite-derived climate data transformed after a harmonic regression, (b) summarizing of data over a tessellation of the territory, and (c) using methods for supervised classification of prevalence categories. However, the use of a limited number of classification methods could also result in a bias, since not every available method has been tested, and because some methods may perform better than others giving data imbalance and other peculiarities in the capture of the environmental niche associated with records of $\mathrm{Bb}$ [21]. We previously included in modelling the landscape fragmentation, which has been pointed as a driver of tick abundance [36], since habitat fragmentation promotes host movements [37]. Small patches would promote ecotones, which are interfaces between different types of vegetation, therefore allowing a greatest rate of hosts movements [13]. However, the modelling methods

Table 2 Performance of the four classification methods used to predict the prevalence of B. afzelii, B. garinii, and B. valaisiana in a grid of $0.25^{\circ}$ radius over Europe using a combination of environmental data

\begin{tabular}{|c|c|c|c|c|c|c|}
\hline & \multicolumn{2}{|c|}{ B. afzelii } & \multicolumn{2}{|c|}{ B. garinii } & \multicolumn{2}{|c|}{ B. valaisiana } \\
\hline & AUC & CA & AUC & CA & AUC & CA \\
\hline Neural Networks & 0.491 & 0.972 & 0.585 & 0.963 & 0.496 & 0.989 \\
\hline Naive Bayes & 0.550 & 0.626 & 0.592 & 0.662 & 0.824 & 0.775 \\
\hline AdaBoost & 0.499 & 0.974 & 0.500 & 0.961 & 0.500 & 0.989 \\
\hline SVM & 0.816 & 0.987 & 0.816 & 0.981 & 0.844 & 0.995 \\
\hline
\end{tabular}

AUC area under the curve, CA classification accuracy. The AUC values refer to the average of all the classifications. Complete AUC and CA values for each category can be obtained from the Additional files 2 and 3 

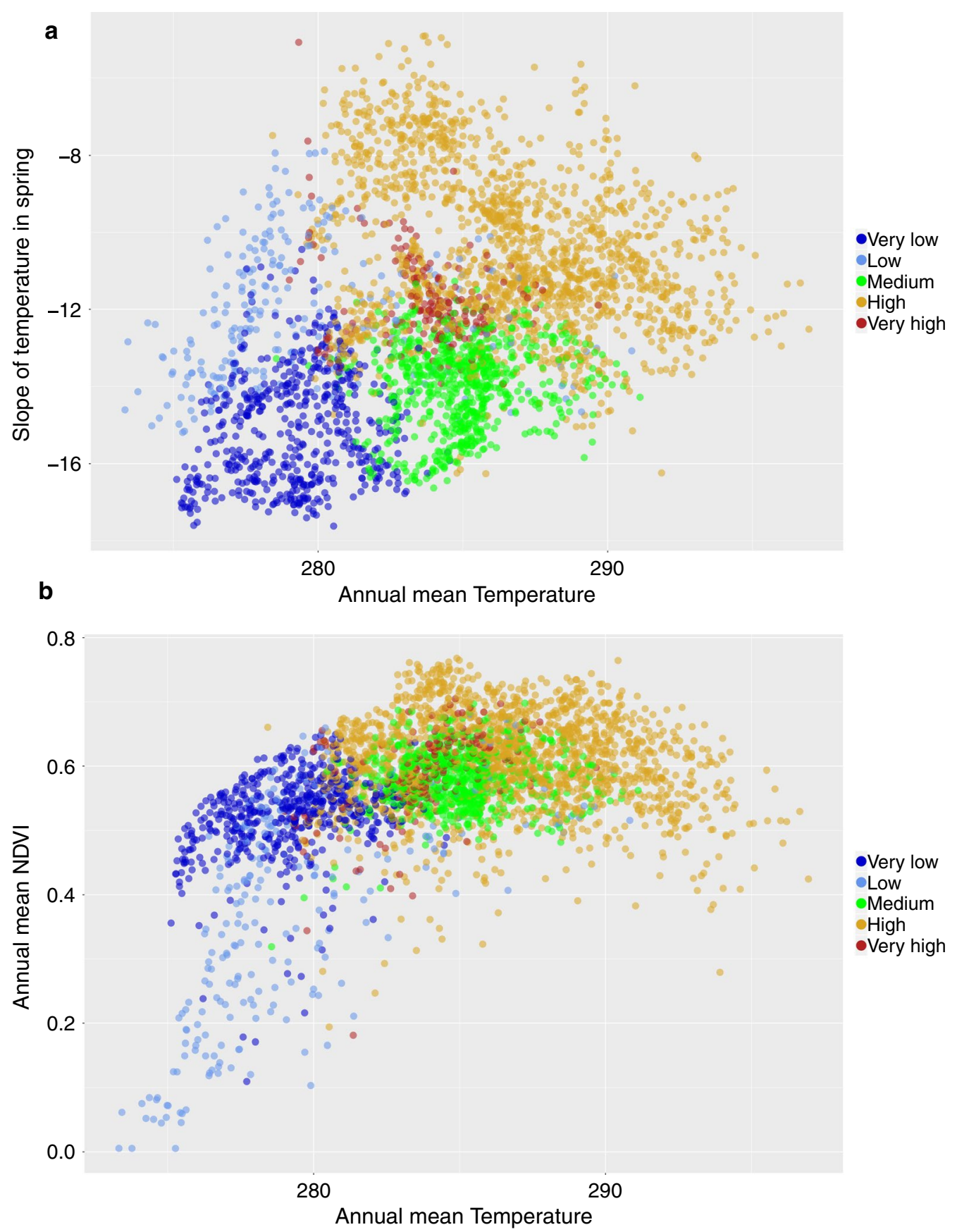

Fig. 9 The distribution of major classes of prevalence of B. afzelii in the environmental axes of a mean annual values of temperature (in Kelvin) versus the slope of temperature in spring (unitless), and $\mathbf{b}$ mean annual values of temperature versus the slope of NDVI in spring for the period 2002-2016. Points of the category "absent" were not plotted to improve readability

systematically rejected the inclusion of landscape patchiness in the best models, which agrees with the spatial scale used in this study for modelling $\left(0.25^{\circ}\right)$ probably too large to capture the intrinsic features of the habitats at a local scale. Collectively, the approach looks promising in evaluating the trends of a pathogen that is primarily driven by changes in climate the abundance of adequate reservoirs and social habits [38, 39].

We acknowledge that the structure of the data collection and the non-random reporting introduced a background noise, obscuring the set of ecological traits affecting the distribution of $\mathrm{Bb}$ [40-42]. However, the 

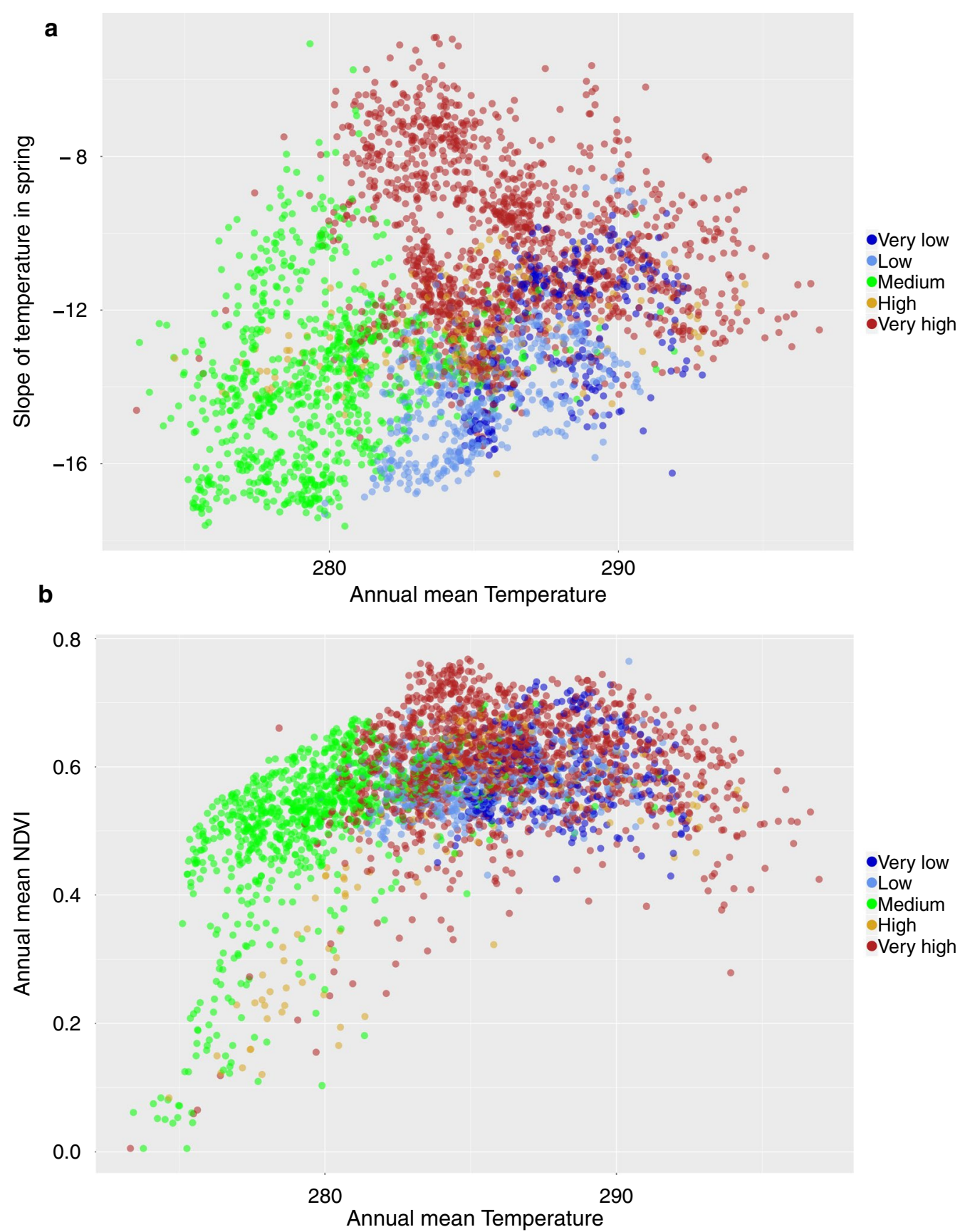

Fig. 10 The distribution of major classes of prevalence of B. garinii in the environmental axes of a mean annual values of temperature (in Kelvin) versus the slope of temperature in spring (unitless), and $\mathbf{b}$ mean annual values of temperature versus the slope of NDVI in spring for the period 2002-2016. Points of the category "absent" were not plotted to improve readability

results confirm a macro-ecological pattern of niche availability for both the tick and the reservoirs, driving the prevalence of the most reported species of $\mathrm{Bb}$. We believe that this effect may be primarily driven by the availability and relative abundance of the main reservoirs, as it has been reported [43]. However, these patterns of climate also delineate the phenology of both the ticks and the vertebrates, therefore shaping their contact rates not only in the geographical background but in the different moments of the year. All these features have a direct impact on the prevalence of $\mathrm{Bb}$ and could be behind the associations of the prevalence with defined portions of 

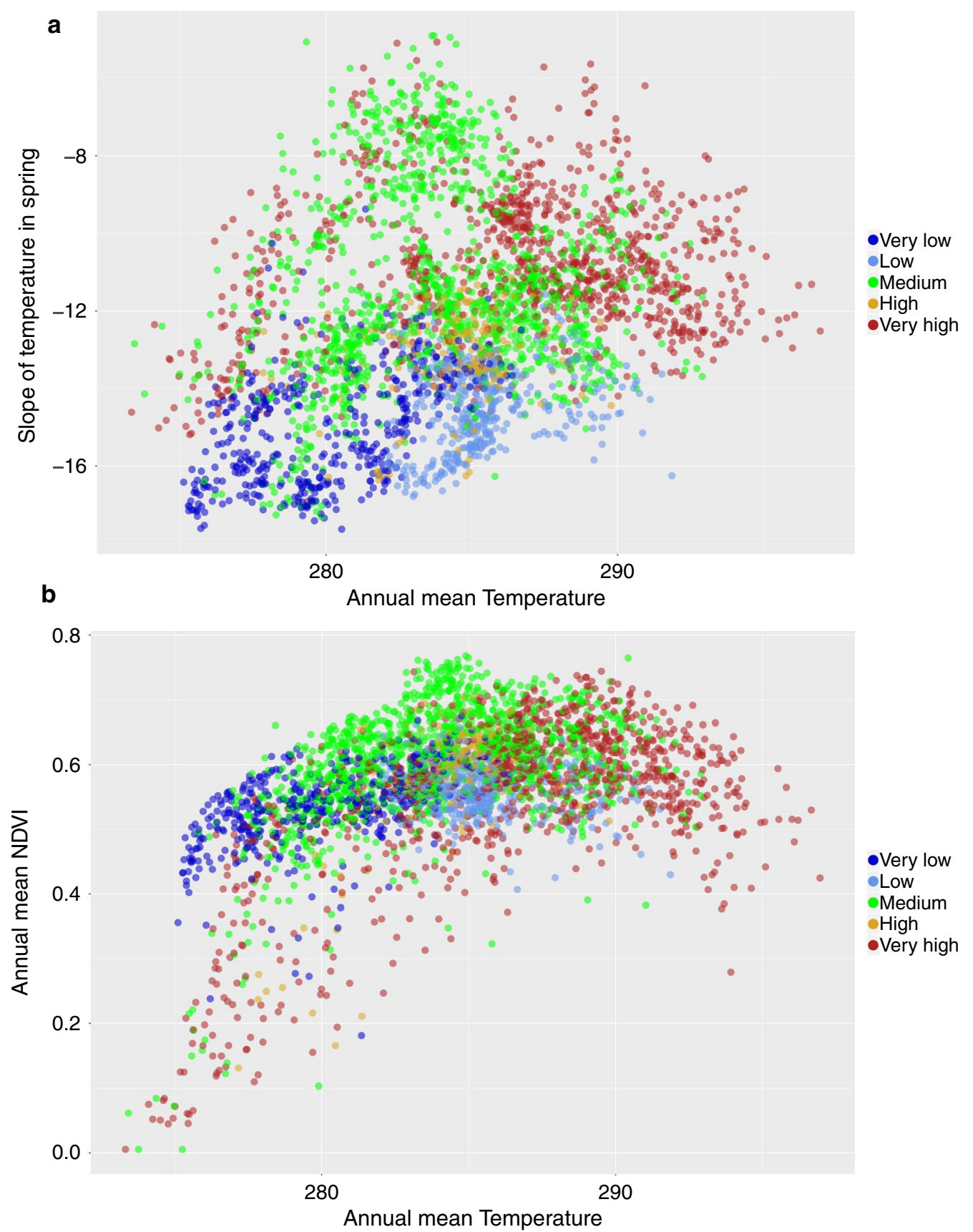

Fig. 11 The distribution of major classes of prevalence of B. valaisiana in the environmental axes of a mean annual values of temperature (in Kelvin) versus the slope of temperature in spring (unitless), and $\mathbf{b}$ mean annual values of temperature versus the slope of NDVI in spring for the period 2002-2016. Points of the category "absent" were not plotted to improve readability

the environmental niche. It is of interest to point out that the most reported $\mathrm{Bb}$ species in Europe have the same spatial distribution, which clearly overlap with the known distribution of the tick I. ricinus $[6,44]$ but at different prevalence.
We thus propose that there is an environmental niche that delineates the prevalence of at least three species of $\mathrm{Bb}$ in ticks in Europe, which are otherwise widely distributed anywhere the vector exists. It also results that any analysis of the effects of climate on the contact rates between ticks and reservoirs should be measured 
in the environmental niche, not in the spatial range, as already proposed [44]. This turns the pure spatial distribution of the pathogen(s) into a statistically meaningful framework. It constitutes a valuable support to explore the impact of climate change on the occurrence of $\mathrm{Bb}$ in a large territory transformed into its niche defined by a combination of environmental variables, like temperature or NDVI. While such framework cannot address local processes, it could estimate long term trends in the prevalence and spread of a medically important bacterium, including future climate projections. It is important to "abandon the map" as the preferred worktable for these studies and assess the impact of change on the dimensions of the environmental niche. The maps of predicted prevalence in $I$. ricinus nymphs should be taken as an indication of exposure to $\mathrm{Bb}$ but not as a mirror of actual human incidence rates. This is widely acknowledged to occur [45] because the complex multi-strain, multi-host interactions associated with $\mathrm{Bb}$ infection make it difficult to determine the risk of infection to humans [46-48]. The lack of reliable data from many European countries, where the incidence in humans is not of mandatory reporting, further complicates the correlation of data between the prevalence of $\mathrm{Bb}$ in questing nymphs and its incidence in humans.

In conclusion, this study updated a previous metaanalysis of the occurrence rates of $\mathrm{Bb}$ in questing nymphs of I. ricinus in Europe. It confirmed previous findings on the largely overlapping distribution of several species of spirochetes reported in the target territory and demonstrated the widespread distribution of three main species. We demonstrated that continuous values of prevalence are of low utility for a solid statistical analysis, and that transformation of these rates into categories provide a better outlook on the epidemiological landscape. The modelling of the prevalence using satellite-derived climate and vegetation data, resulted in a low-resolution model predicting the occurrence of $\mathrm{Bb}$. These results confirm that, at least for the three most commonly reported species of $\mathrm{Bb}$, an association with parts of the environmental niche is evident, most notably involving not only mean values of temperature and NDVI but also the annual phenology of these variables.

\section{Conclusions}

There is an environmental niche driving the prevalence of the most commonly reported species of bacteria of the B. burgdorferi s.l. complex in questing nymphs of I. ricinus ticks. Results obtained from a meta-analysis of more than 82,000 nymphs revealed that B. afzelii, B. garinii and $B$. valaisiana largely overlap across Europe. The highest prevalence occurs in areas of $280^{\circ}-290^{\circ}$ (Kelvin) of mean annual temperature (around central Europe and southern parts of Nordic countries) and a slow spring rise of temperature, together with high mean values and a moderate spring rise of vegetation vigor. Models using a support vector machine based on satellite derived, Fourier-transformed variables, identified ranges of prevalence for these three most commonly reported species in Europe. These results are of special interest not only for delineating areas of risk for humans, but also that the prevalence of the bacteria in ticks can be associated to models based on scenarios of climate change and used to track possible changes in prevalence.

\section{Additional files}

Additional file 1. The complete raw data on the prevalence of Borrelia spp. in questing nymphs of Ixodes ricinus. The columns of the file include "Year Of study", the "Species" of Borrelia spp., "Latitude" and "Longitude" of the original report, "Prevalence" of the original report, and "Sample" (number of questing ticks included in the original report). Included are also the values obtained from each environmental variable (TFourier1 to TFourier 3 , and VFourier 1 to VFourier 3, meaning for the three coefficients of the harmonic regression of MODIS-derived variables).

Additional file 2 . The script used for the best modelling algorithms. The script must to be used with the Additional file 3 (see below) and using the freely available software "Orange" (available at https://orange.biolab.si). The script is open to modify any starting conditions of the algorithms and for examining the predictive power of each algorithm for the different species of Borrelia.

Additional file 3. The dataset with grid data and prevalence categories for the three most commonly reported species of Borrelia spp. in the target territory. The dataset must to be used to start the modelling analysis using the script in Additional file 2. It contains data about habitat suitability of the tick vector (column Prob_ricinus) as well as the six temperature (TFourier1 to TFourier 3) and vegetation variables (VFourier1 to VFourier3). Also included (but not used by modelling algorithms in the resolution of the best modelling approach) are "Level 4" (the top category in the hierarchy of bioclimate regions in the LANMPA2 scheme), "GlobCovMaj" (dominant vegetation according to the GlobalCov scheme), "GlobCovDiv" (landscape fragmentation in the cell as the number of different categories of vegetation). The remaining three columns "clas_afzelii", "clas_garinii" and "clas-valaisiana" refer to the category of repavlence of each of the three modelled species of $\mathrm{Bb}$.

\section{Abbreviations}

Bb: Borrelia burgdorferi sensu lato; NDVI: Normalized Difference Vegetation Index; SVM: support vector machine.

\section{Authors' contributions}

Every co-author participated in the study design. AEP and ADM conducted the bibliographical search. AEP did the analyses, prepared the maps, and wrote the draft manuscript. Every co-author revised the results and read the original draft. All authors read and approved the final manuscript.

\footnotetext{
Author details

${ }^{1}$ Department of Animal Health, Faculty of Veterinary Medicine, Miguel Servet 177, 50013 Zaragoza, Spain. ${ }^{2}$ School of Health, Sport and Bioscience, University of East London, London, UK. ${ }^{3}$ Department of Veterinary Medicine, Faculty of Agriculture, University of Novi Sad, Novi Sad, Serbia. ${ }^{4}$ INRA, UMR BIPAR INRA, ENVA, Anses, Maisons-Alfort, France. ${ }^{5}$ Surveillance and Response Support Unit, Solna, Sweden. ${ }^{6}$ Present Address: Institute of Tropical Medicine, Unite of Medical Entomology, Antwerp, Belgium. ${ }^{7}$ Office of the Chief Scientist Unit, European Centre for Disease Prevention and Control, Solna, Sweden.
} 
${ }^{8}$ Department of Parasitology and Parasitic Diseases, University of Agricultural Sciences and Veterinary Medicine Cluj-Napoca, Cluj-Napoca, Romania.

\section{Acknowledgements}

Not applicable.

\section{Competing interests}

The authors declare that they have no competing interests.

\section{Availability of data and materials}

The dataset(s) supporting the conclusions of this article are included within the article (and its additional file(s).

\section{Consent for publication}

Not applicable.

\section{Ethics approval and consent to participate}

Not applicable.

\section{Funding}

This paper was funded under the Tender of ECDC "ECDC OJ/24/04/2014PROC/2014/013: Guidance, data collection and scientific advice on tick-borne diseases".

\section{Publisher's Note}

Springer Nature remains neutral with regard to jurisdictional claims in published maps and institutional affiliations.

Received: 16 September 2018 Accepted: 27 November 2018 Published online: 04 December 2018

\section{References}

1. Burgdorfer W, Barbour AG, Hayes SF, Benach JL, Grunwaldt E, Davis JP. Lyme disease: a tick-borne spirochetosis? Science. 1982;216:1317-9.

2. Steere AC, Grodzicki RL, Kornblatt AN, Craft JE, Barbour AG, Burgdorfer W, Schmid GP, Johnson E, Malawista SE. The spirochetal etiology of Lyme disease. New Engl J Med. 1983;308:733-40.

3. Lane RS, Piesman J, Burgdorfer W. Lyme borreliosis: relation of its causative agent to its vectors and hosts in North America and Europe. Ann Rev Entomol. 1991;36:587-609.

4. Radolf JD, Caimano MJ, Stevenson B, Hu LT. Of ticks, mice and men: understanding the dual-host lifestyle of Lyme disease spirochaetes. Nat Rev Microbiol. 2012;10:87.

5. Strnad M, Hönig V, Růžek D, Grubhoffer L, Rego RO. Europe-wide metaanalysis of Borrelia burgdorferi sensu lato prevalence in questing Ixodes ricinus ticks. Appl Environ Microbiol. 2017;83:e00609-17.

6. Estrada-Peña A, Alexander N, Wint GW. Perspectives on modelling the distribution of ticks for large areas: so far so good? Parasites Vectors. 2016;9:179-88

7. Kurtenbach K, Hanincová K, Tsao J, Margos G, Fish D, Ogden NH. Fundamental processes in the evolutionary ecology of Lyme borreliosis. Nat Rev Microbiol. 2006;4:660.

8. Korenberg El, Gorelova NB, Kovalevskii YV. Ecology of Borrelia burgdorferi sensu lato in Russia. In: Gray J, Kahl O, Lane RS, Stanek G, editors. Lyme borreliosis: biology, epidemiology and control. Wallingford: CABI Publishing; 2002. p. 175-200.

9. Margos G, Vollmer SA, Ogden NH, Fish D. Population genetics, taxonomy, phylogeny and evolution of Borrelia burgdorferi sensu lato. Infect Genet Evol. 2011:11:1545-63.

10. Miyamoto K, Masuzawa T. Ecology of Borrelia burgdorferi sensu lato in Japan and East Asia. In: Gray J, Kahl O, Lane RS, Stanek G, editors. Lyme borreliosis: biology, epidemiology and control. Wallingford: CABI Publishing; 2002. p. 201-22.

11. Estrada-Peña A, Álvarez-Jarreta J, Cabezas-Cruz A. Reservoir and vector evolutionary pressures shaped the adaptation of Borrelia. Infect Genet Evol. 2018. https://doi.org/10.1016/j.meegid.2018.03.023.
12. Medlock JM, Hansford KM, Bormane A, Derdakova M, Estrada-Peña A, George JC, Kazimirova M. Driving forces for changes in geographical distribution of Ixodes ricinus ticks in Europe. Parasites Vectors. 2013;6:1.

13. Hubálek Z, Halouzka J. Distribution of Borrelia burgdorferi sensu lato genomic groups in Europe, a review. Eur J Epidemiol. 1997;13:951-7.

14. Hubálek Z, Halouzka J. Prevalence rates of Borrelia burgdorferi sensu lato in host-seeking Ixodes ricinus ticks in Europe. Parasitol Res. 1998;84:167-72.

15. Rauter $C$, Hartung T. Prevalence of Borrelia burgdorferi sensu lato genospecies in Ixodes ricinus ticks in Europe: a metaanalysis. Appl Environ Microbiol. 2005;71:7203-16.

16. Estrada-Peña A, Ortega C, Sánchez N, DeSimone L, Sudre B, Suk JE, Semenza JC. Correlation of Borrelia burgdorferi sensu lato prevalence in questing /xodes ricinus ticks with specific abiotic traits in the western Palearctic. Appl Environ Microbiol. 2011;77:3838-45.

17. Bugmyrin SV, Bespyatova LA, Korotkov YS, Burenkova LA, Belova OA, Romanova LI, leshko EP. Distribution of Ixodes ricinus and I. persulcatus ticks in southern Karelia (Russia). Ticks Tick Borne Dis. 2013;4:57-62.

18. Jaenson TGT, Värv K, Fröjdman I, Jääskeläinen A, Rundgren K, Versteirt $\checkmark$, Golovljova I. First evidence of established populations of the taiga tick Ixodes persulcatus (Acari: Ixodidae) in Sweden. Parasites Vectors. 2016;9:377.

19. Jore $S$, Viljugrein $H$, Hofshagen $M$, Brun-Hansen $H$, Kristoffersen $A B$, Nygård K, Ytrehus B. Multi-source analysis reveals latitudinal and altitudinal shifts in range of Ixodes ricinus at its northern distribution limit. Parasites Vectors. 2011;4:84

20. Jore $\mathrm{S}$, Vanwambeke $\mathrm{SO}$, Viljugrein $\mathrm{H}$, Isaksen $\mathrm{K}$, Kristoffersen AB, Woldehiwet Z, Larsen IL. Climate and environmental change drives Ixodes ricinus geographical expansion at the northern range margin. Parasites Vectors. 2014;7:11.

21. Jaenson TGT, Lindgren E. The range of Ixodes ricinus and the risk of contracting Lyme borreliosis will increase northwards when the vegetation period becomes longer. Ticks Tick Borne Dis. 2011;2:44-9.

22. Jaenson TGT, Jaenson DG, Eisen L, Petersson E, Lindgren E. Changes in the geographical distribution and abundance of the tick /xodes ricinus during the past 30 years in Sweden. Parasites Vectors. 2012;5:8

23. Mysterud A, Easterday WR, Stigum VM, Aas AB, Meisingset EL, Viljugrein $\mathrm{H}$. Contrasting emergence of Lyme disease across ecosystems. Nat Commun. 2016;7:11882.

24. Tokarevich NK, Tronin AA, Blinova OV, Buzinov RV, Boltenkov VP, Yurasova ED, Nurse J. The impact of climate change on the expansion of Ixodes persulcatus habitat and the incidence of tick-borne encephalitis in the north of European Russia. Glob Health Action. 2011;4:8448.

25. Qviller L, Viljugrein H, Loe LE, Meisingset EL, Mysterud A. The influence of red deer space use on the distribution of Ixodes ricinus ticks in the landscape. Parasites Vectors. 2016;9:545.

26. Wagemakers A, Staarink PJ, Sprong H, Hovius JW. Borrelia miyamotoi: a widespread tick-borne relapsing fever spirochete. Trends Parasitol. 2015:31:260-9

27. Estrada-Peña A, Gray JS, Kahl O, Lane RS, Nijhoff AM. Research on the ecology of ticks and tick-borne pathogens-methodological principles and caveats. Front Cell Infect Microbiol. 2013;3:29.

28. Estrada-Peña A, Estrada-Sánchez A, de la Fuente J. A global set of Fouriertransformed remotely sensed covariates for the description of abiotic niche in epidemiological studies of tick vector species. Parasites Vectors. 2014;7:302-11.

29. Estrada-Peña A, de la Fuente J, Latapia T, Ortega C. The impact of climate trends on a tick affecting public health: a retrospective modeling approach for Hyalomma marginatum (Ixodidae). PLOS ONE. 2015;10:e0125760.

30. Barandika JF, Olmeda SA, Casado-Nistal MA, Hurtado A, Juste RA, Valcárcel F, García-Pérez AL. Differences in questing tick species distribution between Atlantic and continental climate regions in Spain. J Med Entomol. 2014:48:13-9.

31. Mücher CA, Klijn JA, Wascher DM, Schaminée JH. A new European Landscape Classification (LANMAP): a transparent, flexible and user-oriented methodology to distinguish landscapes. Ecol Indic. 2010;10:87-103.

32. Fingerle V, Schulte-Spechtel UC, Ruzic-Sabljic E, Leonhard S, Hofmann H, Weber K, Pfister K, Strle F, Wilske B. Epidemiological aspects and molecular characterization of Borrelia burgdorferi s.l. from southern Germany with 
special respect to the new species Borrelia spielmanii sp. nov. Int J Med Microbiol. 2008;298:279-90.

33. Richter D, Postic D, Sertour N, Livey I, Matuschka FR, Baranton G. Delineation of Borrelia burgdorferi sensu lato species by multilocus sequence analysis and confirmation of the delineation of Borrelia spielmanii sp. nov. Int J Syst Evol Microbiol. 2006;56:873-81.

34. Margos G, Lane RS, Fedorova N, Koloczek J, Piesman J, Hojgaard A Fingerle V. Borrelia bissettiae sp. nov. and Borrelia californiensis sp. nov. prevail in diverse enzootic transmission cycles. Int J Syst Evol Microbiol. 2016;66:1447-52.

35. Gray JS, Kahl O, Robertson JN, Daniel M, Estrada-Peña A, Gettinby G, Kurtenbach K. Lyme borreliosis habitat assessment. Z Bakteriol. 1998;287:211-28.

36. Estrada-Peña A. Understanding the relationships between landscape connectivity and abundance of Ixodes ricinus ticks. Exp Appl Acarol. 2002;28:239-48

37. Estrada-Peña A. The relationships between habitat topology, critical scales of connectivity and tick abundance Ixodes ricinus in a heterogeneous landscape in northern Spain. Ecography. 2003;26:661-71.

38. Simon JA, Marrotte RR, Desrosiers N, Fiset J, Gaitan J, Gonzalez A, Logan T. Climate change and habitat fragmentation drive the occurrence of Borrelia burgdorferi, the agent of Lyme disease, at the northeastern limit of its distribution. Evol Appl. 2014;7:750-64.
39. Van Duijvendijk G, Sprong H, Takken W. Multi-trophic interactions driving the transmission cycle of Borrelia afzelii between Ixodes ricinus and rodents: a review. Parasites Vectors. 2015;8:643.

40. Yang ZR. Biological applications of support vector machines. Biological applications of support vector machines. Brief Bioinform. 2004:5:328-38.

41. Guo Q, Kelly M, Graham CH. Support vector machines for predicting distribution of Sudden Oak Death in California. Ecol Model. 2005:182:75-90.

42. Drake JM, Randin C, Guisan A. Modelling ecological niches with support vector machines. J Appl Ecol. 2006:43:424-32.

43. Franke J, Hildebrandt A, Dorn W. Exploring gaps in our knowledge on Lyme borreliosis spirochaetes—updates on complex heterogeneity, ecology, and pathogenicity. Ticks Tick Borne Dis. 2013;4:11-25.

44. Estrada-Peña A, de La Fuente J. Species interactions in occurrence data for a community of tick-transmitted pathogens. Sci Data. 2016;3:160056.

45. Rizzoli A, Hauffe HC, Carpi G, Vourc'h Gl, Neteler M, Rosà R. Lyme borreliosis in Europe. Euro Surveill. 2011:16:19906.

46. Brisson D, Dykhuizen DE, Ostfeld RS. Conspicuous impacts of inconspicuous hosts on the Lyme disease epidemic. Proc Biol Sci. 2008;275:227-35.

47. Brooks $\mathrm{CP}$, Zhang $\mathrm{H}$. A null model of community disassembly effects on vector-borne disease risk. J Theor Biol. 2010;264:866-73.

48. LoGiudice K, Duerr STK, Newhouse MJ, Schmidt KA, Killilea ME, Ostfeld RS Impact of host community composition on Lyme disease risk. Ecology. 2008;89(10):2841-9.
Ready to submit your research? Choose BMC and benefit from:

- fast, convenient online submission

- thorough peer review by experienced researchers in your field

- rapid publication on acceptance

- support for research data, including large and complex data types

- gold Open Access which fosters wider collaboration and increased citations

- maximum visibility for your research: over 100M website views per year

At BMC, research is always in progress.

Learn more biomedcentral.com/submissions 